\title{
Comparison of Physicochemical Surface Conditioning Methods for Adhesion of bis-GMA Resin Cement to Particulate Filler Composite and Surface Characterization
}

Òzcan, Mutlu ; De Araujo Michida, Silvia M ; Sipahi, Cumhur ; Souza, Rodrigo O A ; Lombardo, Geraldo ; Takahashi, Fernando E ; Nascente, P

DOI: https://doi.org/10.1080/00218464.2013.804406

Posted at the Zurich Open Repository and Archive, University of Zurich ZORA URL: https://doi.org/10.5167/uzh-100657

Journal Article

Accepted Version

Originally published at:

Özcan, Mutlu; De Araujo Michida, Silvia M; Sipahi, Cumhur; Souza, Rodrigo O A; Lombardo, Geraldo; Takahashi, Fernando E; Nascente, P (2014). Comparison of Physicochemical Surface Conditioning Methods for Adhesion of bis-GMA Resin Cement to Particulate Filler Composite and Surface Characterization. Journal of Adhesion, 90(7):569-584.

DOI: https://doi.org/10.1080/00218464.2013.804406 


\title{
Comparison of Physicochemical Surface Conditioning Methods for Adhesion of bis-GMA Resin Cement to Particulate Filler Composite and Surface Characterization
}

\author{
MUTLU ÖZCAN ${ }^{1}$, SILVIA M. DE ARAUJO MICHIDA ${ }^{2}$, CUMHUR SIPAHI $^{3}$, RODRIGO O.A. SOUZA ${ }^{2}$, \\ GERALDO LOMBARDO ${ }^{2}$, FERNANDO. E. TAKAHASHI ${ }^{2}$ and P. NASCENTE ${ }^{2}$
}

${ }^{1}$ Dental Materials Unit, University of Zürich, Center for Dental and Oral Medicine, Clinic for Fixed and Removable Prosthodontics and Dental Materials Science, Zurich, Switzerland

${ }^{2}$ Department of Dental Materials and Prosthodontics, Dental School, São Paulo State University, São Paulo, Brazil

${ }^{3}$ Department of Prosthodontics, Center for Dental Sciences, Gülhane Military Medical Academy, Ankara, Turkey

Running title: Adhesion of resin cement to particulate filler composite

Part of this study has been presented at the 84th General Session and Exhibition of the International Association for Dental Research (IADR), March, 9-12th, 2005, Baltimore, USA.

Address correspondance to Mutlu Özcan, University of Zürich, Center for Dental and Oral Medicine, Dental Materials Unit, Plattenstrasse 11, 8032 CH, Zurich, Switzerland. E-mail: mutluozcan@hotmail.com 


\section{Abstract}

This study compared the effect of physicochemical surface conditioning methods on the adhesion of bis-GMA based resin cement to particulate filler composite (PFC) used for indirect dental restorations. PFC blocks $\left(N_{\text {block }}=54, n_{\text {block }}=9\right.$ per group) were polymerized and randomly subjected to one of the following surface conditioning methods: a) No conditioning (Control-C), b) Hydrofluoric acid etching (HF) for $60 s$ (AE60), c) HF for $90 \mathrm{~s}$ (AE90), d) HF for $120 \mathrm{~s}$ (AE120), e) HF for $180 \mathrm{~s}$ (AE180) and f) air-abrasion with $30 \mu \mathrm{m}$ silica coated alumina particles $(A B)$. The conditioned surfaces were silanized with an MPS silane and an adhesive resin was applied. Resin composite blocks were bonded to PFC using resin cement and photo-polymerized. PFCcement-resin composite blocks were cut under coolant water to obtain bar specimens (1 $\mathrm{mm} \times 0.8 \mathrm{~mm}$ ). Microtensile bond strength test ( $\mu$ TBS) was performed in a universal testing machine $(1 \mathrm{~mm} / \mathrm{min})$. After debonding, failure modes were classified using stereomicroscopy. Surface characterization was performed on a set of separate specimen surfaces using Scanning Electron Microscopy (SEM), X-Ray Dispersive Spectroscopy (XDS), X-Ray Photoelectron Spectroscopy (XPS) and Fourier Transform Raman Spectroscopy

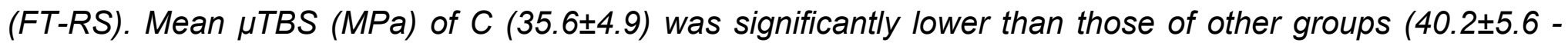

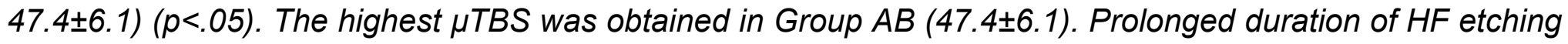

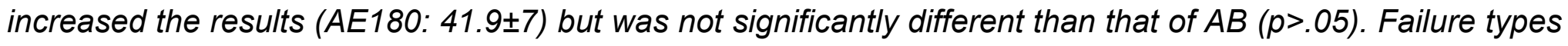
were predominantly cohesive in PFC (34 out of 54) followed by cohesive failure in the cement (16 out of 54). Degree of conversion of the PFC was $63 \pm 10 \%$. SEM analysis showed increased irregularities on PFC surfaces with the increased etching time. Chemical surface analyses with XPS and FT-RS indicated 11 to $70 \%$ silane on the PFC surfaces that contributed to improved bond strength compared to Group $C$ that presented $5 \%$ silane, which seemed to be a threshold. Group $A B$ displayed $83 \% \mathrm{SiO}_{2}$ and $17 \%$ silane on the surfaces.

KEYWORDS: Adhesion; Direct Composite Resin; Indirect Composite Resin; FT-RS; Microtensile Bond Strength; XPS; XDS 


\section{INTRODUCTION}

Due to their optical properties and the possibility to make minimal invasive restorations, the use of particulate filler composite (PFC) materials has increased considerably during the last two decades in dentistry [1]. Although resin-based composite materials are known to offer significant benefits and advantages, polymerization shrinkage, which is commonly believed to be the primary cause of marginal gap formation, microleakage and subsequent pulpal pathology, continues to be an inherent disadvantage [2]. The physical properties of restorations made of PFCs are improved when the PFC is free of voids and the resin matrix is maximally polymerized. In order to fabricate dense and well-polymerized PFC restorations, the PFC is best polymerized in a dental laboratory using polymerization devices providing accurate pressure, vacuum, light, and heat conditions $[3,4]$.

The indirect restorations made of PFCs are considered as an alternative restorative method for minimizing the disadvantage of shrinkage. Residual internal stresses existing in the composite resin matrix are eliminated by extraoral polymerization that enhances both physical and mechanical properties of the material [3-5]. On the other hand, material manipulation out of the mouth allows better proximal contacts, morphology, and adjustment of occlusal surface. Clinical indications for PFC indirect restorations are dictated by the amount of the remaining tooth structure, intraoral conditions, and the cost of the therapy [6]. Indirect PFC restorations are commonly indicated when maximum wear resistance is required, when proper contours and contact would be difficult to achieve intraorally, and when a ceramic restoration is not indicated because of the concerns on the wear of opposing dentition $[4,5,7]$. In addition, laboratory-processed PFC inlays/onlays are more resistant to occlusal wear than directly applied resin composites, have good optical properties, and also possess potential for repair [7].

PFC materials are usually classified according to the size of their inorganic particles. Hybrid PFCs contain particles greater than $1 \mu \mathrm{m}$, microhybrid PFCs have particles smaller than $1 \mu \mathrm{m}$, and nano-hybrid PFCs have 
particles smaller than $0.4 \mu \mathrm{m}$. The increase in the size and the volume of inorganic particles improves their wear resistance, decreases the polymerization contraction and increases the polishability, which favours the optical properties [3].

The degree of conversion (DC) plays also a significant role on the physical and biological properties of PFC restorations. DC is highly dependent on composition of the material, colour and translucency, distance of the photo-polymerization light source to the surface, and the irradiance of the polymerization lamp. PFCs present higher DC, as polymerization is carried out in the laboratory or at chairside, in special photopolymerization units in which all surfaces of the restoration can be polymerized in a more controlled manner [3]. PFC restorations are then cemented to the dentinal cavities using resin cements that are chemically compatible with the PFCs. However, prior to cementation, physicochemical surface conditioning is a prerequisite for achieving adequate adhesion between the PFC restoration and the resin cement $[4,6]$. Conditioning of the intaglio surfaces of PFC restorations is typically achieved by hydrofluoric acid (HF) etching, air-abrasion followed by silanization, or the combination of them $[6,8]$.

While HF etching and air-abrasion produce a rough intaglio surface for micromechanical retention [9-11], silanization creates a chemical bonding between the resin matrix of the PFC and the adhesive resin, and the subsequent resin cement $[4,11]$. The high percentage of silica particles in some PFCs makes them a good substrate for being etched with HF [12]. Swift et al [13] reported that HF could be detrimental for PFC restorations as it softens the resin surface, leading to porosity. HF could theoretically etch the silica particles and create a retentive surface on the PFC [11,14] depending on the acid concentration [6,14]. While Hooshmand et al [15] emphasized the positive effect of silane application, other studies claimed that mechanical attachment is the most important aspect for adhesion, and silane application seemed to be unnecessary for enhancing the bond strength of resin composite $[7,16,17]$. 
In an attempt to better simulate the intraoral conditions, previous studies evaluated the effect of thermocycling on the adhesion between PFC and resin cement where decreased bond strength was observed between the two substrates $[11,18,19]$. Despite numerous studies exist evaluating the adhesion between PFC and various organic and inorganic substrates with or without silanization, there is sparse data on the best conditioning method for PFC materials to achieve optimum adhesion of resin cements. Furthermore, etching duration seems to be an important factor for glassy matrix ceramics $[20,21]$ but such an effect for PFCs has not been identified yet. Since HF is a hazardous compound [22], it is also of interest to know whether surface conditioning of PFCs with chairside air-abrasion could be a substitute for HF etching.

The objectives of this study were to a) compare the effect of physicochemical surface conditioning methods on the adhesion of bis-GMA based resin cement to PFC used for indirect dental restorations after aging, classify the failure types after debonding and b) analyze the surface chemistry of PFCs before and after conditioning methods.

\section{MATERIALS AND METHODS}

The specifications of the materials used in the present study are listed in Table 1.

\subsection{Specimen Preparation}

A block of brass model $(6 \mathrm{~mm} \times 6 \mathrm{~mm} \times 6 \mathrm{~mm})$ was fabricated and all surfaces of this model were covered with 2 sheets of modeling wax. The wax covered brass model was coated with freshly poured autopolymerizing acrylic resin (Duralay, Reliance Dental, Worth, III) to obtain a custom-made open-ended cubical resin tray. Stoppers with $1.5 \mathrm{~mm}$ length were formed on the inner surfaces of the resin tray to provide a standard thickness for the impression material. The wax sheets were eliminated from the brass model surfaces. The cavity of the resin tray was then filled with freshly poured polyvinyl siloxane elastomeric impression material (Elite HD Putty, Zhermack, Rovigo, Italy) and the brass model was placed into the tray 
cavity. After impression material was set, the metal block was retrieved from the tray, the impression cavity was filled with PFC (Vita VMLC, Vita Zahnfabrik, Bad Säckingen, Germany) and photo-polymerized (Elipar Freelight II, 3M ESPE, Seefeld, Germany) at $600 \mathrm{mw} / \mathrm{cm}^{2}$ light intensity for 40 seconds. PFC blocks $\left(N_{\text {block }}=54\right)$ were obtained using the incremental technique where approximately $1.5 \mathrm{~mm}$ thick resin layers were polymerized in four stages. Final layer was polymerized under a glass slab to obtain flat surfaces. Finally, PFC blocks were further polymerized in a polymerization oven (Visio-Alfa, Visio-Beta, 3M ESPE) according to the manufacturers instructions.

Similarly, composite resin blocks (W3D Master, Wilcos, Sao Paulo, Brazil) (6 mm x $6 \mathrm{~mm}$ x $6 \mathrm{~mm}$ ) were fabricated using the same acrylic resin tray to be bonded to PFC using resin cement. Each layer of composite was photo-polymerized (Elipar Freelight II) at $600 \mathrm{mw} / \mathrm{cm}^{2}$ light intensity for 40 seconds. Composite resin block surfaces were not subjected to any surface conditioning method.

\subsection{Physicochemical Surface Conditioning Methods}

PFC blocks ( $n_{\text {block }}=6$ per group) were randomly assigned to one the following physicochemical surface conditioning methods:

Group C: This group did not receive any conditioning (Control).

Group AE60: PFC specimens in this group were etched with 10\% HF for 60 seconds, rinsed with distilled water and dried with air-spray.

Group AE90: PFC specimens were etched with 10\% HF for 90 seconds rinsed with distilled water and dried with air-spray.

Group AE120: PFC specimens were etched with $10 \%$ HF for 120 seconds rinsed with distilled water and dried with air-spray. 
Group AB: PFC specimens were air-abraded with $30 \mu \mathrm{m}$ silica coated alumina particles (CoJet Sand, 3M ESPE, Seefeld, Germany) using a chairside air-abrasion device (Dento-Prep, RØNVIG, Daugaard, Denmark) from a distance of $10 \mathrm{~mm}$, with the nozzle perpendicular to surface at a pressure of 2.8 bars.

\subsection{Silanization and Cementation}

3-methacryloxypropyltrimethoxy silane (MPS) coupling agent (Monobond-S, Ivoclar Vivadent, Schaan Liechtenstein) was applied on the conditioned PFC surfaces using microbrush. After evaporation of the silane solvent (5 minutes), adhesive resin (Excite DSC, Ivoclar Vivadent) was applied onto the silanized surfaces, air-thinned and polymerized for 10 seconds. Then, composite resin blocks were bonded onto the conditioned PFC surfaces using a dual-polymerized bis-GMA based resin cement (Variolink II, Ivoclar Vivadent) according to the instructions of the manufacturer.

During cementation, PFC blocks were positioned and secured with their conditioned surfaces exposed and following application of resin cement onto the PFC surface, composite resin block was placed on the PFC. A constant weight of $750 \mathrm{~g}$ was applied onto the cemented substrates for 5 minutes [23]. During this period, light (Elipar Freelight II) was applied from 4 sites of the cemented interfaces for 40 seconds. After completion of the cementation procedure, blocks of PFC-cement-composite resin assemblies (6 mm x $6 \mathrm{~mm} \times 12 \mathrm{~mm})$ were obtained (Fig. 1a).

The assemblies were kept in distilled water at room temperature for 24 hours, and then subjected to thermal cycling (Willytech, Gräfelfing, Germany) for 6000 cycles between $5^{\circ} \mathrm{C}-55^{\circ} \mathrm{C}$, with a dwell time of 30 seconds at each temperature.

\subsection{Preparation of Specimens for Microtensile Bond Test ( $\mu$ TBS)}

The PFC-composite resin blocks were vertically bonded with cyanoacrylate (Super Bonder Gel, Loctite Ltd, Piracicaba, Brazil) on the metal platform of a high-speed cutting lathe (Smedent, RL-S24, Shanghai, China) 
(Fig. 1b). A diamond disc (diameter: $5 \mathrm{~mm}$; thickness: $0.75 \mathrm{~mm}$ ) was used for the cuttings procedures. The blocks were cut initially longitudinally in 3 equal slices $(1.5 \mathrm{~mm} \times 6 \mathrm{~mm} \times 12 \mathrm{~mm}$ ) (Fig. 1b). Each of the 3 slices was cut again longitudinally in additional 3 equal slices from which finally 9 PFC-composite resin bars $\left(1.5 \mathrm{~mm} \times 1.5 \mathrm{~mm} \times 12 \mathrm{~mm}\right.$; cement interface area: $\left.1.5 \times 1.5=2.25 \mathrm{~mm}^{2}\right)$ were obtained (Fig. 1c).

The size of each specimen was measured before the test with a digital micrometer (Starret Indústria e Comércio Ltd., São Paulo, Brazil) at a precision of centesimal millimeter to control specimen dimensions. Specimens out of standard were eliminated and new specimens were fabricated. In total, 54 bars were obtained for each group.

For $\mu$ TBS test, each specimen was fixed on a custom made jig to position the cemented interface perpendicular to the tensile axis in order to avoid generation of shear forces. The jig was then fixed on the universal testing machine (EMIC DL1000, Equipamentos e Sistemas Ltd., São José dos, Pinhais, Brazil) and tensile load was applied at a crosshead speed of $0.5 \mathrm{~mm} / \mathrm{min}$ until debonding occurred between the PFC and resin composite. The maximum force values $(\mathrm{N})$ at failure were obtained, converted to $\mathrm{MPa}\left(\mathrm{N} / \mathrm{mm}^{2}\right)$ and recorded.

Following the $\mu$ TBS test, the debonded surfaces of the specimens were first examined with a stereomicroscope (Optical Microscope, CARL ZEISS, Stemi 2000-C, Göttingen, Germany) at x50 magnification and were subsequently observed under Scanning Electron Microscope (SEM) (Jeol-JSMT330A, Scanning Microscope, Tokyo, Japan) for failure analysis.

\subsection{Surface Characterization}

Additional PFC blocks were fabricated $\left(\mathrm{N}_{\text {block }}=12, \mathrm{n}_{\text {block }}=2\right.$ per conditioning group) as described above. Topographical changes were analyzed from conditioned surfaces using SEM at x500 - x2000 magnification. X-ray Dispersive Spectroscopy (XDS), X-ray Photoelectron Spectroscopy (XPS) analyses were performed in order to detect chemical composition of the PFC surfaces. Both techniques were complementary to each 
other and were used to detect the HF acid activity and amount of silica particles exposed from the organic matrix. The XPS technique not only allows the detection of the atoms present on the surface but also gives information about the presence of functional groups (i.e. $-\mathrm{C}=\mathrm{C}-,-\mathrm{OH}$ ) that would be able to influence the union between the PFC and the resin cement interface.

In addition, Fourier Transform Raman Spectroscopy (FT-RS) (RFS 100/S, Bruker Inc, Karlsruhe, Germany) was used to determine the degree of conversion (DC) of PFC specimens. For this purpose another set of PFC blocks were fabricated $\left(\mathrm{N}_{\text {block }}=12\right)$ as described above. The specimens were stored in distilled water at $37^{\circ} \mathrm{C}$ for $24 \mathrm{~h}$ prior to the analysis. The top and bottom surfaces of the blocks were analyzed by FTRS. The Raman peaks corresponding to the vibrational stretching modes at 1610 and $1640 \mathrm{~cm}^{-1}$ were fitted in Gaussian shapes to obtain the height of the peaks by Microcal Origin Software (Microcal Software Inc, Northampton, MA, USA). A comparison of the height ratio of the aliphatic carbon-carbon double bond $(\mathrm{C}=\mathrm{C})$ at $1640 \mathrm{~cm}^{-1}$ with that of the aromatic component at $1610 \mathrm{~cm}^{-1}$ for the polymerized and unpolymerized conditions was performed in order to estimate the DC according to the following equation [24]:

$$
R_{\text {unpolymerized }}=\frac{\text { band height at } 1640 \mathrm{~cm}^{-1}}{\text { band height at } 1610 \mathrm{~cm}^{-1}}
$$

The mean and standard deviation of the DC were calculated where $R$ is the percentage of unpolymerized resin that is determined by band height at $1640 \mathrm{~cm}^{-1} /$ band height at $1610 \mathrm{~cm}^{-1}$.

$$
R_{\text {polymerized }}=\frac{\text { band height at } 1640 \mathrm{~cm}^{-1}}{\text { band height at } 1610 \mathrm{~cm}^{-1}}
$$

where $\mathrm{R}$ is the ratio of polymerized resin that is determined by band height at $1640 \mathrm{~cm}^{-1} /$ band height at 1610 $\mathrm{cm}^{-1}$.

The percentage of DC was then calculated using the following equation: 


$$
\mathrm{DC}(\%)=100 \times\left[1-\left(R_{\text {polymerized }} / \mathrm{R}_{\text {unpolymerized }}\right)\right]
$$

\subsection{Statistical Analysis}

Statistical analysis was performed using SPSS 11.0 software for Windows (SPSS Inc., Chicago, IL, USA).

Bond strength data were analyzed with a statistical software program (SPSS 15.0 for Windows, SPSS Chicago, III). The analysis of variance (ANOVA) test was used to determine significant differences between control groups and experimental groups. Due to significant differences between groups, multiple comparisons were made using Dunnett's test. $P$ values less than 0.05 were considered to be statistically significant in all tests.

\section{RESULTS}

\section{1. $\mu$ TBS Bond Strength and Failure Types}

Surface conditioning methods significantly affected the $\mu$ TBS results $(p<.05)$. Mean $\mu$ TBS (MPa) of Group $C$ $(35.6 \pm 4.9)$ was significantly lower than those of the other 5 groups $(40.2 \pm 5.6-47.4 \pm 6.1)(p<.05)$ (Table 2, Fig. 2). The highest $\mu$ TBS was obtained in Group $A B(47.4 \pm 6.1)$. Prolonged duration of HF etching for 180

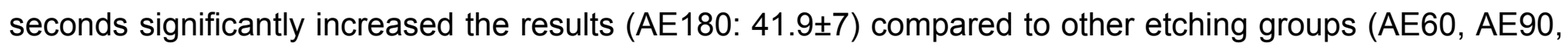
AE120). Etching duration between 60 to 120 seconds did not show significant differences $(p>.05)$. No significant difference was observed between $A E 180$ and $A B(p>05)$.

Overall the failure types were predominantly cohesive in PFC (34 out of 54) followed by cohesive failure in the cement (16 out of 54 ). The remaining 4 specimens showed cohesive failure in the composite resin.

\subsection{Surface Characterization}

SEM analysis showed that 180 seconds of etching time increased irregularities on PFC surfaces compared to the control group and the other acid etched groups (Figs. 3a-j). In Group AE180 organic matrix was partially dissolved, forming deep fissures. Group $A B$ also showed a rough pattern, protruding from the PFC surface 
due to particle deposition that possibly enhanced micromechanical attachment of the resin cement (Figs. 3kI).

XPS analysis indicated considerable amounts of $\mathrm{Si}$ in groups $\mathrm{C}$ and AE60. Si amount was $83 \%$ in Group $A B$, in which the PFC surfaces were silica coated.

C-C and/or C-H amount observed in C (64\%) decreased to 56\% in Group AE60 and 53\% in Group AE180 according to XPS analysis (Table 3). Despite HF etching procedures, no F but a very low quantity of $\mathrm{N}$ was detected on the conditioned PFC surfaces.

Regarding to the formation of $\mathrm{OH}$, adsorbed oxygen, $\mathrm{C}=\mathrm{O}, \mathrm{C}-\mathrm{O}$ and $\mathrm{H}_{2} \mathrm{O}$, the percentage of those bounds increased or diminished without displaying any correlation with the conditioning method. Chemical surface analyses indicated 11 to $70 \%$ silane on the PFC surfaces that possibly contributed to improved bond strength compared to the Group C that presented only $5 \%$ silane, which seemed to be a threshold in this group. On the other hand, Group AB displayed $17 \%$ silane on the surfaces.

Degree of conversion of the PFC was $63 \pm 10 \%$.

\section{DISCUSSION}

This study was undertaken in order to find the best physicochemical conditioning method for the adhesion of bis-GMA based resin cement to PFC used for indirect dental restorations and to gain some insight on surface chemistry changes after conditioning methods. Based on the results of this study, it can be stated that either etching with HF at different durations or chairside air-abrasion using alumina particles coated with silica could be advised for conditioning the cementation surfaces of the PFC tested. All conditioning methods presented significantly higher results than that of the control group indicating that physicochemical conditioning prior to cementation is a prerequisite. The non-significant difference in mean bond strength values between Groups 
$A E 180$ and $A B$, also supported by the SEM images, denotes that the micromechanical retention achieved after these two conditioning methods played a significant role in improving adhesion.

The bond strength data should to be coupled with the failure type analysis. Predominantly cohesive failures observed in the PFC, indicate that the adhesive strength at the interface exceeded the cohesive strength of the PFC material. On the other hand, cohesive failures in the cement layer imply also good adhesion but weaker cohesive strength of the cement. In principle in both failure types, reliable adhesion could be expected. The quality of polymer network formed during the polymerization procedure may also affect the bond strength. Even though the polymerization process of the PFC was achieved in a polymerization device under heat and vacuum, DC (63\%) was not very high that potentially left free monomers on the surface to react with the silane, the subsequent adhesive resin and the resin cement. It is thought that less cross-linking provides a more flexible structure that resists tensile forces better, increasing the toughness and thereby decreasing the fragility at the interface. This in turn leads to frequent cohesive failure types. Polymer networks with high cross-linking density reduce covalent cross-links. Thus, in this case, the presence of carbon chains available on the surface might polymerize together with the resin cement. In the resin composite chain, the terminal carbon atom can form a cross link with the carbon atom of the resin cement to be polymerized. This may explain the high bond strength values obtained in all experimental groups and the insignificant difference especially between AE60 to AE120.

The high incidence of cohesive failures obtained in the present study is in agreement with that of a previous study [25], providing that in that study shear bond test was applied. On the other hand, these findings contradicted the findings of Swift et al [13] who observed a high percentage of adhesive failures in HF etched resin composite groups. This difference may be attributed to the relatively shorter etching time applied in the study of Swift et al, being insufficient to produce sufficient roughness on resin surfaces for 
micromechanical retention. In the present study, the minimal increase in etching time from 120 to 180 seconds increased bond strength to PFC surfaces.

SEM analysis of etched groups showed progressively rougher surfaces compared to the control group with the extended etching time. Group AE180 showed higher dissolution of the organic resin phase, with formation of deep fissures. Despite these findings, the bond strength of Group AE180 was not drastically higher than those of other etched groups. Thus, it can be said that micromechanical retention due to the dissolution of the silica particles corroborates with the adhesion obtained by silane coupling agent. Consequently, the synergistic action of the silane adds to the bond between the PFC molecules and resin cement.

$\mathrm{HF}$ acid is able to dissolve glassy matrix and crystalline compounds of the feldspathic ceramics or inorganic fillers in the organic matrix of the PFC selectively, depending on the acid concentration [6]. The subsequent application of silane, recommended by some manufacturers, allows wetting of the internal surface of the restoration developing the bond strength between the restoration and the resin cement. Silane is a bifunctional molecule that bonds to the inorganic particles in the resin matrix and to the adhesive systems, allowing molecules to react with the methacrylate groups of the bonding agent [25]. Contrary to these reports, Swift et al [13] and Brosh et al [14] claimed that silane application could not promote a stronger bond and emphasized that mechanical retention is the most important aspect for chemical union of the substrate and the adherent. The chemical analysis performed in the present study showed that silane application contributed to a stronger bonding and corroborates for the improved bond strength. All groups showed higher amounts of silane (11-70\%) on the surface than the control group (5\%). In the present study, SEM and chemical analyses showed the presence of silica particles on resin surfaces even after etching procedures. Thus, it can be assumed that siloxane bonds could be formed after the application of silane. According to Hooshmand et al [15], keeping silanized specimens in water did not negatively affect the effect 
of silane, and that silane application for a long term bonding is a prerequisite. Additionally, Shahdad and Kennedy [8] reported that silanes display a high surface wetting on resin surfaces that improves the adhesion process, which may all have contributed to higher bond strength compared to the control group.

The results of SEM, EDS and XPS revealed that the etching of PFC surfaces with HF for $90 \mathrm{~s}$ (group AE90) caused a decrease in the amount of silica on the surface and an increase in the amount of oxygen and carbon. This fact can be explained with the acidic reaction between molecular carbon chains and chemical bonding between surface molecules of resin composite with resin cement molecules after silane and bonding agent application. The XPS analysis revealed variable percentage of carbon bonds $(C-C, C=C C=O, O-C=O)$, as well as variable Si percentage while the etching time increased. The hypothesis that could explain this fact would be the chemical ablation of the HF leading to a "peeling" of the resin composite surface. The acid would act on the surface dissolving and/or exposing silica particles and reacting with the organic matrix and eventually decomposing the matrix [6]. Yet, the amount of chemical components of the experimental groups was not very different compared to the negative control group. Possibly prolonged application duration of HF gel may change the surface chemistry. This aspect coupled with silane-based surface modifications needs to be further verified with contact angle and wettability measurements in future studies.

According to Özcan and Vallittu [22] the durability of the values of bond strength of the material under oral environment is important for the prognostic of the dental material. Generally, those materials are subjected to thermal, mechanical and chemical variations in the mouth during oral functions. Storage in water and thermal cycling are common ways for testing the stability of dental materials and its conveniences in vitro. Söderholm and Roberts [17] observed that the more the composite resins are stored in water the weaker their resistance and the higher their hydrolytic degradation. In this study, aging was performed for 6000 times in a thermocycle machine at alternating temperatures between 5 and $55^{\circ} \mathrm{C}$. Controversial reports are present 
discussing aging effect of thermocycling $[6,17]$. In future studies it has to be identified whether long term water storage has impact of aging at the bonded interface similar to thermocycling.

Several testing methodologies, (i.e. macroshear, microshear, macrotensile, and microtensile tests) have been suggested for evaluation of the bond strength of resin-based materials to dental materials. Hence, to measure the bond strength values between an adherent and a substrate accurately, it is crucial that the bonding interface should be the most stressed region, regardless of the test methodology being employed. Previous studies using stress distribution analyses have reported that some of the bond strength tests do not appropriately stress the interfacial zone $[27,28]$. Shear tests have been criticized for the development of nonhomogeneous stress distributions in the bonded interface, inducing either underestimation or misinterpretation of the results, as the failure often starts in one of the substrates and not at the adhesive zone [26]. Although conventional tensile tests also present some limitations, such as the difficulty of specimen alignment and the tendency for heterogeneous stress distribution at the adhesive interface, this type of test was proposed to provide information on global bond strength. On the other hand, the microtensile test allows better alignment of the specimens, and a more homogeneous distribution of stress, in addition to a more sensitive comparison or evaluation of bond performances [28]. For this reason in this study microtensile test was employed. Typically, in such a test method, bonded blocks are used as statistical unit and usually six blocks are advised when adhesion of resin based materials to dentin is tested. Since dentin is a heterogeneous substrate having different tubuli orientations, this approach may deliver more acceptable statistical power for adhesion tests on dentin. In that respect, PFC material used can be considered a more homogenous substrate. Hence, less number of specimens was used in this study. Future studies may consider verification of the results with higher number of specimens. Nevertheless, since no pre-test failures were experienced during cutting the blocks, it can be stated that the adhesion of all groups are satisfactory. 
When there are clinical considerations regarding the hazardous effects of HF acid, prior to cementation, airabrasion followed by silanization may substitute this conditioning method for the PFC used.

\section{CONCLUSIONS}

From this study the following could be concluded:

1- Surface conditioning of particulate filler composite studied, showed the highest microtensile bond strength of the bis-GMA based resin cement either after $10 \%$ hydrofluoric acid etching for 180 seconds or air-abrasion with alumina particles coated with silica followed by silanization.

2- Etching with $10 \%$ hydrofluoric acid for 60 to 120 seconds was less effective in terms of bond strength and increased etching time increased the surface irregularities.

3- Regardless of the conditioning method, failure types were predominantly cohesive in the particulate filler composite.

4- Chemical surface analyses (XDS, XPS and FT-RS) indicated 11 to $70 \%$ silane on the surface that possibly contributed to improved bond strength compared to the control group that presented only $5 \%$ silane, where the latter could be considered a threshold for silane amount needed.

\section{ACKNOWLEDGEMENTS}

The authors would like to acknowledge Prof. M. Bottino, Department of Dental Materials and Prosthodontics, Dental School, São Paulo State University, for providing the particulate filler composite materials and Mr. Ivan Balducci for his assistance with the statistical analysis. 


\section{REFERENCES}

[1] O'Brien W.J., Dental Materials and Their Selection. $4^{\text {th }}$ ed, (Quintessence Publishing Co, Hanover Park, Chicago, 2008) p.114.

[2] Kramer N., Lohbauer U., and Frankenberger R., Adhesive luting of indirect restorations. Am. J. Dent. 13, 60-76 (2000).

[3] Souza R.O.A., Özcan M., Michida S.M.A., de Melo R.M., Pavanelli C.A., Bottino M.A., Soares L.E.S., and Martin A.A., Conversion degree of indirect resin composites and effect of thermocycling on their physical properties. J. Prosthodont. 19, 218-225 (2010).

[4] Türkmen C., Durkan M., Cimilli H., and Öksüz M., Tensile bond strength of indirect composites luted with three new self-adhesive resin cements to dentin. J. Appl. Oral Sci. 19, 363-369 (2011).

[5] Gerdolle D.A., Mortier E., Loos-Ayav C., Jacquot B., and Panighi M.M., In vitro evaluation of microleakage of indirect composite inlays cemented with four luting agents. J. Prosthet. Dent. 93, 563-570 (2005).

[6] Özcan M., Alander P., Vallittu P.K., Huysmans M.C., and Kalk W., Effect of three surface conditioning methods to improve bond strength of particulate filler resin composites. J. Mater. Sci. Mater. Med. 16, 21-27 (2005).

[7] Soares C.J., Giannini M., Oliveira M.T., Paulilio L.A.M.S., and Martins L.R.M., Effects of surface treatments of laboratory-fabricated composites on the microtensile bond strength to a luting resin cement. $J$. Appl. Oral Sci. 12, 45-50 (2004).

[8] Shadhad A.S., and Kennedy J.G., Bond strength of repaired anterior composite resins: an in vitro study. J. Dent. 26, 685-694 (1998). 
[9] Kula K., Nelson S., and Thompson V., In vitro effect of APF gel on three composite resins. J. Dent. Res. 62, 846-849 (1983).

[10] Saunders W.P., Effect of fatigue upon the interfacial bond strength of repaired composite resins J. Dent. Res. 18,158-162 (1990).

[11] Öztas N., Alaçam A., and Bardakey Y., The effect of air abrasion with two bonding agents on composite repair. Oper Dent. 28,149-154 (2003).

[12] Touati B., The evolution of aesthetic materials for inlays and onlays: a review. Pract. Periodontol. Aesthet. Dent. 8, 657-666 (1996).

[13] Swift E.J., Jr. Brodeur C., Cvitko E., and Pires J.A.F., Treatment of composite surfaces for indirect bonding. Dent. Mater. 8, 193-196 (1992).

[14] Brosh T., Pilo R., Bichacho N., and Blutstein R., Effect of combinations of surface treatments and bonding agents on the bond strength of repaired composites J. Prosthet. Dent. 77, 122-126. (1997).

[15] Hooshmand T., Van Noort R., and Keshvad A., Bond durability of the resin-bonded and silane treated ceramic surface. Dent. Mater. 18, 179-188 (2002).

[16] Söderholm K.J., and Roberts M.J., Variables influencing the repair strength of dental composites Scand. J. Dent. Res. 99, 173-180 (1991).

[17] Söderholm K.J., Zigan M., Ragan M., Fischlschweiger W., and Bergman M., Hydrolytic degradation of dental composites. J. Dent. Res. 63, 1248-1254 (1984). 
[18] Lucena-Martín C., González-López S., and Mondelo J.M.N.R., The effect of various surface treatments and bonding agentes on the repaired strength of heat-treated composites J. Prosthet. Dent. 86, 481-488 (2001).

[19] Özcan M., and Vallittu P.K., Effect of surface conditioning methods on the bond strength of luting cement to ceramics Dent Mater. 19, 725-731 (2003).

[20] Turkmen C. Durkan M., Oksuz M., Shear bond strength of indirect composites luted with three new selfadhesive resin cements to dentin. J. Adhes. 85, 919-931 (2009).

[21] Leite F.P., Özcan M., Valandro L.F., Moreira C., Amaral R., Bottino M.A., and Kimpara E.T., Effect of the etching duration and ultrasonic cleaning on microtensile bond strength between feldspathic ceramic and resin cement. J. Adhes. 89, 159-173 (2013).

[22] Özcan M., Allahbeickaraghi A., and Dündar M., Possible hazardous effects of hydrofluoric acid and recommendations for treatment approach: a review. Clin Oral Investig. 16, 15-23 (2012).

[23] Marocho S.M., Özcan M., Amaral R., Valandro L.F., and Bottino M.A., Effect of seating forces on cement-ceramic adhesion in microtensile bond tests. Clin. Oral. Investig. 17, 325-331 (2013).

[24] Khalil S.K., Allam M.A., and Tawfik W.A., Use of FT-Raman spectroscopy to determine the degree of polymerization of dental composite resin cured with a new light source. Eur J Dent. 1, 72-79 (2007).

[25] Bouschlicher M., Cobb D.S., and Vargas M.A., Effect of two abrasive systems on resin bonding to laboratory processed indirect resin composite restorations. J. Esthet. Dent. 11, 185-196 (1999).

[26] Matinlinna J.P., Lassila L.V., Özcan M., Yli-Urpo A., and Vallittu P.K., An introduction to silanes and their clinical applications in dentistry. Int. J. Prosthodont. 17, 155-164 (2004). 
[27] Sudsangiam S., and van Noort R., Do dentin bond strength tests serve a useful purpose? J. Adhes. Dent. 1, 57-67 (1999).

[28] Valandro L.F., Özcan M., Amaral R., Vanderlei A., and Bottino M.A., Effect of testing methods on the bond strength of resin to zirconia-alumina ceramic: microtensile versus shear test. Dent. Mater. J. 27, 849-55 (2008). 


\section{Captions to tables and figures:}

\section{Tables:}

TABLE 1 Types, brands, batch numbers and manufacturers of the materials used in the present study.

TABLE 2 Descriptive statistics (mean, standard deviations, coefficient of variation, minimum, maximum values) of microtensile bond strength values $(\mathrm{MPa})$ of particulate filler composite-resin cement. Same uppercase letters indicate no significant differences in one column (Dunnett test at $95 \%$ confidence level). C: Non-conditioned control group; AE60: Hydrofluoric acid etching for 60 seconds; AE90: 90 seconds; AE120: 120 seconds; AE180: 180 seconds; AB: Air-abrasion with alumina particles coated with silica.

TABLE 3 Chemical components (\%) on the particulate filler composite in control and experimental groups determined by XPS analysis. "Energy linking references with variation of \pm 0.3 ; Calibration: $\mathrm{C} 1 \mathrm{~s} 284.6 \mathrm{eV}$.

\section{Figures:}

FIGURES 1A-C. a) Particulate filler composite-resin cement-resin composite assembly vertically bonded to metal holder, b) Diamond coated disc cutting the block assembly, c) Bar specimen obtained for microtensile bond strength test.

FIGURE 2. Column graphic of mean microtensile bond strength (MPa) and standard deviations of the experimental groups.

FIGURE 3. SEM images of particulate filler composites (C, AE60, AE90, AE120, AE180, AB) at x500 and x2000 magnification, respectively. Note that 180 seconds of etching time increased irregularities in the form of fissures on the surfaces compared to the control group and the other acid etched groups. $A B$ conditioning created also a rough pattern with protrusions from the surfaces. 
Tables:

\begin{tabular}{|c|c|c|}
\hline Material Type & $\begin{array}{l}\text { Brand and Batch } \\
\text { numbers }\end{array}$ & Manufacturer \\
\hline Particulate Filler Composite & $\begin{array}{l}\text { Vita VMLC } \\
\text { Batch: } 13200\end{array}$ & $\begin{array}{l}\text { VITA Zahnfabrik, } \\
\text { Bad Säckingen, } \\
\text { Germany }\end{array}$ \\
\hline Direct composite resin & $\begin{array}{l}\text { W3D MASTER } \\
\text { Batch: } 007 / 06\end{array}$ & $\begin{array}{l}\text { Wilcos do Brasil Com, } \\
\text { RJ, Brazil }\end{array}$ \\
\hline Hydrofluoric acid (10\%) & $\begin{array}{l}\text { Porcelain Conditioner } \\
\text { Batch: } 634113\end{array}$ & $\begin{array}{l}\text { Dentsply, Petrópolis, } \\
\text { RJ, Brazil }\end{array}$ \\
\hline Silane & $\begin{array}{l}\text { Monobond-S } \\
\text { Batch: H24764 }\end{array}$ & $\begin{array}{l}\text { Ivoclar Vivadent, } \\
\text { Liechtenstein, Schaan }\end{array}$ \\
\hline Adhesive Resin & $\begin{array}{l}\text { Excite DSC (Regular) } \\
\text { Batch: H } 23024\end{array}$ & Ivoclar Vivadent \\
\hline Resin cement (Base) & $\begin{array}{l}\text { Variolink II } \\
\text { (Opaque White) } \\
\text { Batch: J } 19033\end{array}$ & Ivoclar Vivadent \\
\hline Resin cement (Catalyst) & $\begin{array}{l}\text { Variolink II } \\
\text { (Shade A3) } \\
\text { Batch: J } 09824\end{array}$ & Ivoclar Vivadent \\
\hline $\begin{array}{l}\text { Silica coated aluminium } \\
\text { oxide particles }(30 \mu \mathrm{m})\end{array}$ & $\begin{array}{l}\text { CoJet-Sand } \\
\text { Batch: } 0006\end{array}$ & $\begin{array}{l}\text { 3M ESPE, Seefeld, } \\
\text { Germany }\end{array}$ \\
\hline Polymerization oven & $\begin{array}{l}\text { Visio-Alfa } \\
\text { Serial \#: } 900021000229\end{array}$ & 3M ESPE \\
\hline Polymerization oven & $\begin{array}{l}\text { Visio-Beta } \\
\text { Serial \#: } 910012000169\end{array}$ & 3M ESPE \\
\hline
\end{tabular}


TABLE 1 Types, brands, batch numbers and manufacturers of the materials used in the present study.

\begin{tabular}{|c|c|c|c|c|c|}
\hline $\begin{array}{c}\text { Groups } \\
\text { (n=9 per }\end{array}$ & $\begin{array}{c}\text { Mean } \\
\text { (MPa) }\end{array}$ & $\begin{array}{c}\text { Standard } \\
\text { Deviation }\end{array}$ & $\begin{array}{c}\text { Coefficient of } \\
\text { Variation (\%) }\end{array}$ & Minimum & Maximum \\
\hline group) & & & & \\
\hline $\mathbf{C}$ & $35.64^{\mathrm{a}}$ & 4.95 & 13.88 & 29.59 & 41.26 \\
\hline AE60 & $40.20^{\mathrm{b}}$ & 5.63 & 14.00 & 31.78 & 46.21 \\
\hline AE90 & $40.96^{\mathrm{b}}$ & 5.18 & 12.65 & 33.46 & 45.88 \\
\hline AE120 & $40.61^{\mathrm{b}}$ & 3.17 & 7.80 & 36.23 & 44.52 \\
\hline AE180 & $41.86^{\mathrm{c}}$ & 7.01 & 16.74 & 32.26 & 49.61 \\
\hline AB & $47.38^{\mathrm{c}}$ & 6.12 & 12.93 & 38.02 & 54.79 \\
\hline
\end{tabular}

TABLE 2 Descriptive statistics (mean, standard deviations, coefficient of variation, minimum, maximum values) of microtensile bond strength values (MPa) of particulate filler composite-resin cement. Same uppercase letters indicate no significant differences in one column (Dunnett test at 95\% confidence level). C: Non-conditioned control group; AE60: Hydrofluoric acid etching for 60 seconds; AE90: 90 seconds; AE120: 120 seconds; AE180: 180 seconds; AB: Air-abrasion with alumina particles coated with silica. 


\begin{tabular}{|c|c|c|c|c|c|c|c|}
\hline $\begin{array}{c}\text { Components } \\
(\%)\end{array}$ & Linking Energy $(\mathrm{eV})^{*}$ & C & AE60 & AE90 & AE120 & AE180 & AB \\
\hline $\mathrm{C}-\mathrm{C}, \mathrm{C}-\mathrm{H}$ & 284.6 & 64 & 56 & 64 & 66 & 53 & 55 \\
\hline $\mathrm{C}-\mathrm{O}, \mathrm{C}-\mathrm{N}$ & 286.3 & 23 & 19 & 24 & 14 & 23 & 12 \\
\hline $\mathrm{C}=\mathrm{O}, \mathrm{O}-\mathrm{C}=\mathrm{O}$ & 288.6 & 13 & 11 & 12 & 4 & 10 & 2 \\
\hline $\mathrm{N}-\mathrm{C}$ & 399.2 & 100 & 100 & 100 & 100 & 100 & 91 \\
\hline $\mathrm{OH}, \mathrm{O}$ & 530 & 13 & 14 & 23 & 19 & 18 & 18 \\
\hline$C=O$ & 532 & 66 & 54 & 59 & 52 & 58 & 25 \\
\hline $\mathrm{C}-\mathrm{O}, \mathrm{H}_{2} \mathrm{O}$ & 533.2 & 21 & 25 & 18 & 21 & 18 & 51 \\
\hline Silane & 102.5 & 5 & 11 & 70 & 15 & 26 & 17 \\
\hline $\mathrm{SiO}_{2}$ & 103.5 & 95 & 88 & 30 & 85 & 74 & 83 \\
\hline
\end{tabular}

TABLE 3 Chemical components (\%) on the particulate filler composite in control and experimental groups determined by XPS analysis. *Energy linking references with variation of \pm 0.3 ; Calibration: $\mathrm{C} 1 \mathrm{~s} 284.6 \mathrm{eV}$. 
Figures:

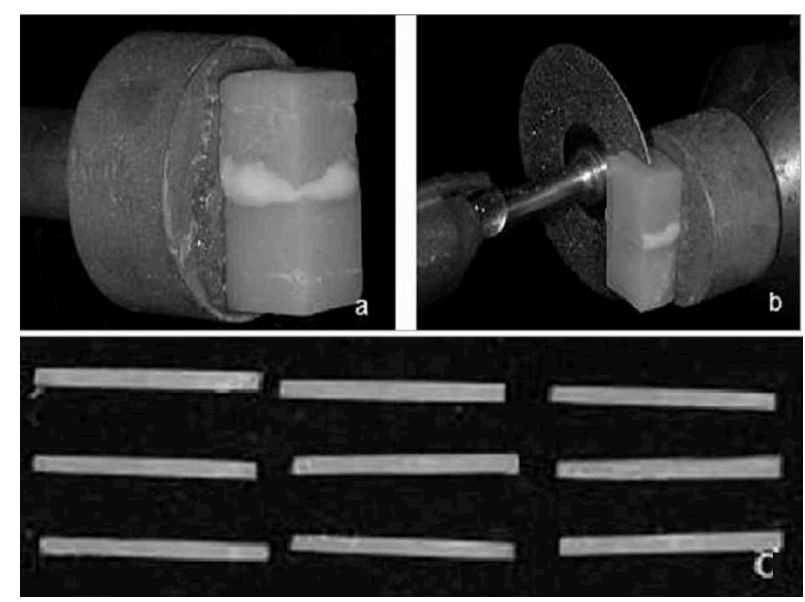

FIGURES 1A-C. a) Particulate filler composite-resin cement-resin composite assembly vertically bonded to metal holder, b) Diamond coated disc cutting the block assembly, c) Bar specimen obtained for microtensile bond strength test.

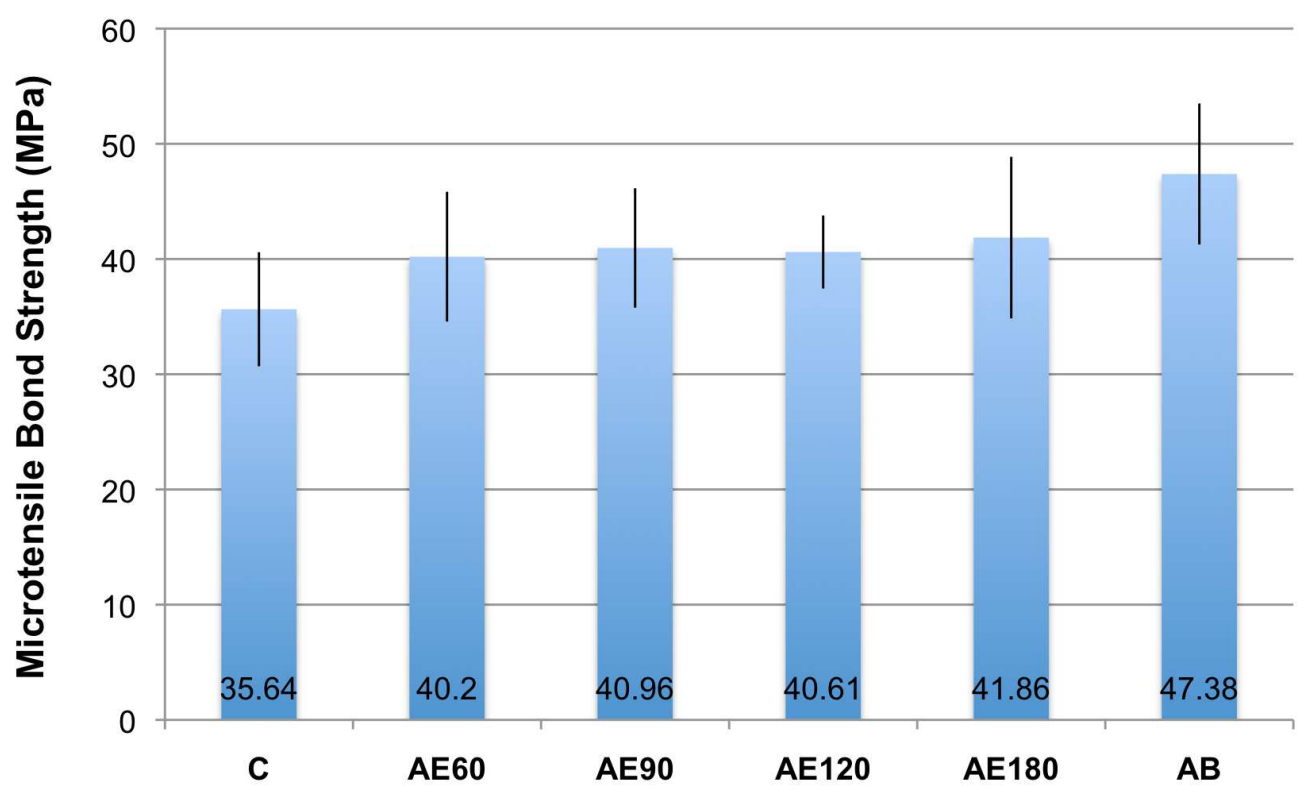

FIGURE 2. Column graphic of mean microtensile bond strength (MPa) and standard deviations of the experimental groups. 

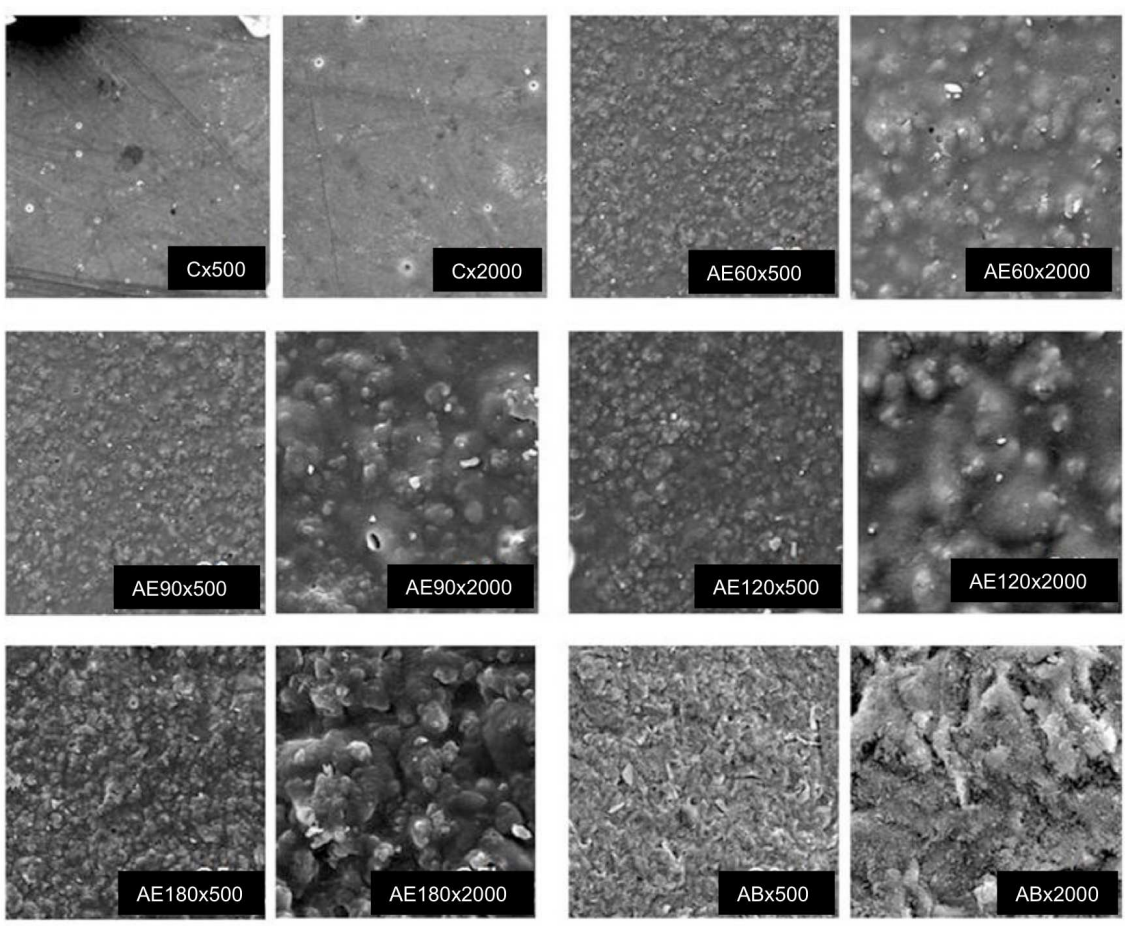

FIGURE 3. SEM images of particulate filler composites (C, AE60, AE90, AE120, AE180, AB) at x500 and x2000 magnification, respectively. Note that 180 seconds of etching time increased irregularities in the form of fissures on the surfaces compared to the control group and the other acid etched groups. AB conditioning created also a rough pattern with protrusions from the surfaces. 